\title{
A survey of familial heart block
}

\author{
C. M. Morgans, ${ }^{1}$ K. E. Gray, and G. H. Robb ${ }^{2}$ \\ From the Cardiac Department, Bristol General Hospital, Bristol
}

\begin{abstract}
Electrocardiograms were recorded in 66 first-degree relatives of patients with complete atrioventricular block. Conduction anomalies were found in Io relatives who belonged to 4 families. The incidence of conduction anomalies is higher than would be expected by chance. Genetic factors may be important in the aetiology of heart block.
\end{abstract}

Familial heart block and sinus bradycardia are well recognized (Sarachek and Leonard, 1972).

When a mother and daughter both presented at the Bristol General Hospital with complete heart block within a period of a year, it was decided to survey as many of their relatives as possible, and also to survey the first-degree relatives of the patients attending the pacemaker clinic, to see how commonly conduction abnormalities occurred.

Our interest was further stimulated by the finding that one of the patients attending the pacemaker clinic, with complete heart block, had 3 sons with hypertrophic cardiomyopathy. This will be the subject of a separate report.

\section{Subjects and methods}

Twenty-two relatives of the mother and daughter who both had complete heart block were examined and had electrocardiograms recorded (Family A); 6 of those examined were first-degree relatives.

The names and addresses of their first-degree relatives were obtained from 64 patients attending the pacemaker clinic. Out of 202 first-degree relatives, 9I lived within a 40-mile radius of Bristol and they were asked if they would consent to examination and the recording of an electrocardiogram. Replies were received from 73, 60 consenting and 13 declining. The 60 relatives came from 28 families. Of the III relatives who lived outside the 40-mile radius, none was known to have either a slow heart rate or a pacemaker.

\section{Results}

The average age of the 6 first-degree relatives from Family A and the 60 first-degree relatives from the

Received 4 February 1974

1 Present address: St. Mary's General Hospital, Milton Road, Portsmouth, $\mathrm{PO}_{3}$ 6AD.

2 Present address: Royal Infirmary, Leicester LEI 5 WW. pacemaker clinic was 53 (range 25 to 79 ). Of the 66 , I8 had abnormal electrocardiograms. In 8 the abnormality was one that was unlikely to be a manifestation of idiopathic heart block; these were changes such as ST segment depression, or either left ventricular hypertrophy or left bundle-branch block in the presence of systemic hypertension. The electrocardiographic changes in the remaining Io relatives, who came from 4 families, are listed in the Table.

\section{Family A: the patients}

Case I A woman of 73 presented in July 1968, having had numerous syncopal attacks in the previous week. Myxoedema had been diagnosed in 1958 and she had received thyroxine since then. In 1967 an autoimmune haemolytic anaemia was diagnosed and this responded to prednisolone. Electrocardiograms recorded in 1958 and I960 showed sinus rhythm with a PR interval of O. I8 sec. After her syncopal attacks an electrocardiogram showed complete heart block with a QRS duration of $0.12 \mathrm{sec}$. The form of the QRS was different from that seen during sinus rhythm. She was successfully treated with a pervenous pacing system, and is alive in 1974 .

Case 2 The daughter of Case I, aged 46, presented in May 1969. For 6 months she had noticed breathlessness and loss of energy, but had had no disturbance of consciousness. Her electrocardiogram showed intermittent complete heart block. Sometimes there was sinus rhythm with a PR interval $0 \cdot 16 \mathrm{sec}$, and at other times there was complete atrioventricular block with a ventricular rate of 45 a minute, but at these times the duration of the QRS complexes was unchanged at $0.08 \mathrm{sec}$ and the form of the QRS complex was similar to that seen when the patient was in sinus rhythm. In February I970 she began to have dizzy attacks and was successfully treated with a pervenous pacing system. She remains alive and well in 1974. 


\section{Family A: the relatives}

Of the 22 examined, 17 were progeny of Case I: 5 children, 7 grandchildren, and 5 great-grandchildren. In addition, I brother of Case I was examined, together with 3 of his children and I great-grandchild.

Seventeen had normal electrocardiograms. The brother of Case I, aged 76, had left anterior hemiblock with a mean QRS frontal plane axis of $-60^{\circ}$. Three of the children of Case I had equivocal QRS frontal plane axis deviation. Two were sons aged 26 and 38 , and one was a daughter aged 52 . In 2 of them, there was a mean frontal plane QRS axis of $-30^{\circ}$, and in one the axis was $+100^{\circ}$.

In total, the 24 members of family $A$ included 2 with complete atrioventricular block, I with left anterior hemiblock, and 3 with probable minor conduction abnormalities. So 6 of the 24 members ( $25 \%$ ) had conduction anomalies.

\section{Family B: the patient}

An obese, 75-year-old woman presented in November I968 with syncopal attacks which were due to complete heart block. A pervenous pacemaker was successfully inserted.

\section{Family B: the relatives}

One brother, 2 sons, and her only daughter had abnormal cardiograms (Table). The brother had bilateral bundlebranch block. One son had partial right bundle-branch block, and the other left anterior hemiblock. The daughter had sinus bradycardia with a heart rate of 40 a minute. She was not clinically hypothyroid and was not in a high state of physical training.

\section{Family C: the patient}

A woman of 62 presented in 1970 with syncopal attacks. Her electrocardiogram showed complete right bundlebranch block, left anterior hemiblock, and first-degree heart block. She was first treated with long-acting oral isoprenaline, but after further syncopal attacks a pervenous pacemaker was inserted.

\section{Family C: the relative}

One of her sons was a 35-year-old serviceman who was symptomless. He had had numerous army medical examinations, and no mention had been made of any cardiac abnormality. There was no past history of diphtheria or rheumatic fever. On examination his pulse was irregular caused by brief pauses punctuating periods of regular rhythm. His blood pressure was $120 / 80 \mathrm{mmHg}$, and, apart from the irregularity, clinical examination of the heart was normal.

His electrocardiogram frequently showed seconddegree atrioventricular block of Mobitz type I. At other times there were prolonged periods of first-degree block with a PR interval of $0.24 \mathrm{sec}$. No other abnormality was seen on the electrocardiogram. After exercise on a bicycle ergometer at $600 \mathrm{kpm}$ for 9 minutes, the electrocardiogram showed a ventricular rate of 135 a minute and a PR interval of $0.16 \mathrm{sec}$, with no second-degree block. A His bundle electrocardiogram (Fig.) showed a $\mathrm{PH}$ interval of $\mathrm{I} 60 \mathrm{msec}$ and an HQ interval of $40 \mathrm{msec}$. In successive cycles the PH interval rose to $220 \mathrm{msec}$ while the $H Q$ interval remained constant. In the following cycle a $\mathbf{P}$ wave was followed by neither an $\mathrm{H}$ deflection nor a QRS complex, indicating atrioventricular block at or above atrioventricular node level.

This relative's brother showed no abnormality on clinical or electrocardiographic examination. The relative's three children were also examined and no abnormality was found.

\section{Family D: the patient}

A 79-year-old woman presented with complete heart block in I968. She had been breathless for a number of years and had then had a number of syncopal attacks. A pervenous pacing system was established successfully.

\section{Family D: the relative}

Her 75-year-old sister who was asymptomatic, had firstdegree heart block, and was not taking any drug likely to cause this.

TABLE Conduction abnormalities in the relatives

\begin{tabular}{|c|c|c|c|c|}
\hline & No. & $A g e(y r)$ & $\begin{array}{l}\text { Relationship to patient } \\
\text { with pacemaker }\end{array}$ & Electrocardiographic abnormality \\
\hline \multirow[t]{4}{*}{ Family A } & $\mathbf{I}$ & 38 & Son & Axis: $-30^{\circ}$ \\
\hline & 2 & 52 & Daughter & Axis: $+100^{\circ}$ \\
\hline & 3 & 26 & Son & Axis: $-30^{\circ}$ \\
\hline & 4 & 76 & Brother & Axis: $-60^{\circ}$ \\
\hline \multirow[t]{4}{*}{ Family B } & I & 70 & Brother & $\begin{array}{l}\text { Right bundle-branch block; } \\
\text { axis: }-60^{\circ}\end{array}$ \\
\hline & 2 & 45 & Son & Partial right bundle-branch block \\
\hline & 3 & 38 & Son & Axis: $-30^{\circ}$ \\
\hline & 4 & 49 & Daughter & Sinus bradycardia (rate: 40 ) \\
\hline Family C & I & 35 & Son & Second-degree heart block \\
\hline Family D & $\mathbf{I}$ & 75 & Sister & First-degree heart block \\
\hline
\end{tabular}

Axis = Mean frontal plane QRS axis. 


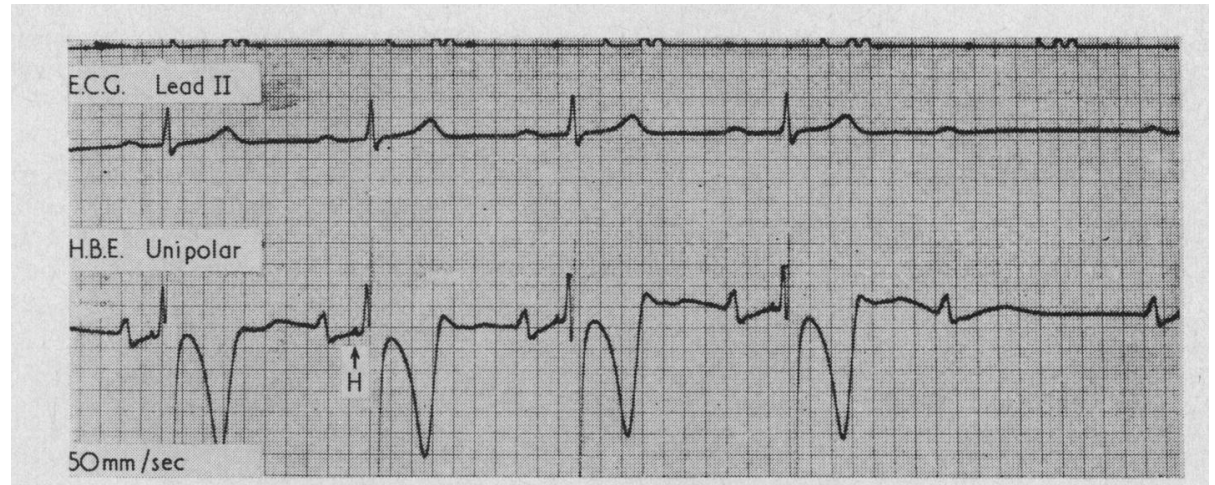

FIG. His bundle electrogram in the relative of Family C. Lead II shows a PR interval of $200 \mathrm{msec}$ after the first $P$ wave. There is an increasing $P R$ interval for the next 3 cycles then $a$ $P$ wave which is blocked. The simultaneous His bundle electrogram shows an increasing interval between the $P$ wave and the $H$ deflection, and the blocked $P$ wave is not followed by an $H$ deflection. This indicates a block above the level of the bundle of His.

\section{Discussion}

Of the 60 relatives who were seen in the survey, 6 (10\%) had conduction anomalies. In an individual subject it is not possible to state whether the anomaly is inherited or acquired, but in these subjects no evidence was found of underlying cardiovascular disease which might cause heart block. These 6 relatives were from 3 of the 28 families surveyed, giving a prevalence of affected families of II per cent. The numbers are small, and a large survey would be needed to find the true incidence of familial heart block, but the familial association of these anomalies is unlikely to be fortuitous. Averill and Lamb (1960) and Johnson, Averill, and Lamb (1960), in a survey of electrocardiographic findings in 67,375 asymptomatic subjects, found only one case of second-degree heart block, and that was probably due to myocarditis. The incidence of complete right bundle-branch block was 0.16 per cent and of the left bundle-branch block 0.02 per cent. However, 90 per cent of their subjects were aged between 20 and 40 years and represent a much younger group than the relatives seen in our survey.

The most striking feature of our results was that 4 of the 6 relatives with a conduction anomaly came from one family; this fact was not recognized until completion of the survey and correlation of the abnormal electrocardiograms with the individual patients attending the pacemaker clinic.

Sarachek and Leonard (1972) reviewed 8 families with heart block of adult onset. In II of the 17 individuals with complete heart block electrocardiograms had been recorded before the development of complete heart block. In all II there were lesser degrees of block present, such as right bundlebranch block, left anterior hemiblock, or first- or second-degree atrioventricular block. In the present study only one of the six pacemaker patients with affected relatives was known to have had a previous electrocardiogram. That was normal, but it had been recorded eight years previously. However, at least two of the patients had electrocardiograms showing right bundle-branch block and left anterior hemiblock at the time of their presentation with syncopal attacks.

It is now well established that complete heart block in adults is frequently caused by bilateral bundle-branch fibrosis of unknown aetiology and not by coronary artery disease (Hudson, 1970). Information is scanty regarding the pathology in adults known to have familial heart block, but one case has been described in which fibrosis was found in the atrioventricular node and the proximal part of the bundle-branches (Tsagaris, Bustamente, and Friesendorff, 1967).

In our survey, the incidence of conduction anomalies in the relatives of patients with complete heart block is much higher than would be expected as a chance finding. It, therefore, seems likely that genetic factors play a part in the development of 'idiopathic' fibrosis of the conducting tissues in heart block of adult onset. If this were not the case it would be necessary to postulate that familial heart block and non-familial heart block were separate diseases and that there was a high incidence of familial heart block in our pacemaker patients.

A large survey and a very long follow-up of affected relatives would be necessary to determine the prognosis of the various conduction anomalies. 
We are grateful to Dr. D. W. Barritt, and Dr. S. C. Jordan for permission to study patients under their care.

\section{References}

Averill, K. H., and Lamb, L. E. (1960). Electrocardiographic findings in 67,375 asymptomatic subjects. I. Incidence of abnormalities. American fournal of Cardiology, 6, 76.

Hudson, R. E. B. (1970). Cardiovascular Pathology, Vol. 3, S.r28. Arnold, London.

Johnson, R. L., Averill, K. H., and Lamb, L. E. (1960). Electrocardiographic findings in 67,375 asymptomatic subjects. VII. Atrioventricular block. American fournal of Cardiology, 6, 153 .

Sarachek, N. S., and Leonard, J. L. (1972). Familial heart block and sinus bradycardia. Classification and natural history. American fournal of Cardiology, 29, 451.
Tsagaris, T. J., Bustamente, R. A., and Friesendorff, R. A. (1967). Familial heart disease. Diseases of the Chest, 52, I53.

\section{Addendum}

Since this paper was submitted a further example of familial heart block has come to light in our clinic, a man aged 79 who presented in 1969. His electrocardiogram showed complete atrioventricular block with a QRS duration of $0.14 \mathrm{sec}$ and right bundle-branch block pattern. He has been treated with a cardiac pacemaker since then. His sister aged 83 presented in January 1974. Her electrocardiogram showed complete heart block with a QRS duration of I-IO sec and QRS complexes of normal configuration.

Requests for reprints to Dr. K. E. Gray, Cardiac Department, Bristol General Hospital, Bristol BSI 6SY. 